University of Nebraska - Lincoln

DigitalCommons@University of Nebraska - Lincoln

Robert G. Fuller Publications and Presentations Research Papers in Physics and Astronomy

June 1968

\title{
Possible trivacancy contribution to ionic conductivity
}

Robert Fuller

rfuller@neb.rr.com

M.H. Reilly

U.S. Naval Research Laboratory, Washington. D.C.

Follow this and additional works at: https://digitalcommons.unl.edu/physicsfuller

Part of the Physics Commons

Fuller, Robert and Reilly, M.H., "Possible trivacancy contribution to ionic conductivity" (1968). Robert G. Fuller Publications and Presentations. 27.

https://digitalcommons.unl.edu/physicsfuller/27

This Article is brought to you for free and open access by the Research Papers in Physics and Astronomy at DigitalCommons@University of Nebraska - Lincoln. It has been accepted for inclusion in Robert G. Fuller Publications and Presentations by an authorized administrator of DigitalCommons@University of Nebraska - Lincoln. 


\title{
Possible trivacancy contribution to ionic conductivity
}

\author{
R. G. Fuller \& M. H. Reilly \\ U.S. Naval Research Laboratory, Washington. D.C. 20390, USA
}

(Submitted June 1968)

Fuller and Reilly [1], Fuller, Reilly, Marquardt and Wells [2], and Allnatt and Pantelis [3] have recently reported the results of measurements of the intrinsic electrical conductivity $\sigma$ of $\mathrm{RbCl}, \mathrm{KCl}$ and $\mathrm{NaCl}$, respectively. All of these results showed an anomalous behavior of the $\log (\sigma T)$ vs. $T^{-1}$ plot at temperatures near the melting points of the various crystals. It is the purpose of this note to discuss the suggestion [4] that the anomaly may be due to a trivacancy mechanism.

The plots of the $\log (\sigma T)$ vs. $T^{-1}$ were found to have too great a positive curvature in the intrinsic region to be described by the usual conductivity equations [5], even when the corrections for Coulomb interactions [6] were used in the analyses [7]. To explain the 6 per cent deviation between their theoretical and experimental results for $\mathrm{NaCl}$ at $794^{\circ} \mathrm{C}$ Allnatt and Pantelis [3] suggested the presence of cationic Frenkel disorder. In their subsequent least squares analysis the interstitial $\mathrm{Na}$ ions were found to carry about 61 per cent of the electrical current in $\mathrm{NaCl}$ at $794^{\circ} \mathrm{C}$. According to the Nernst-Einstein relation the mobile interstitial $\mathrm{Na}$ ions would also make a large contribution to the cation diffusion in $\mathrm{NaCl}$. A large interstitial contribution to $\mathrm{Na}$ diffusion in $\mathrm{NaCl}$ has never been reported [8]. It therefore seems important to point out the characteristics of trivacancy contributions to conductivity.

Trivacancies could exist in the crystal in two types, the cation type $(+-+)$ or the anion type $(-+-)$. Each type of trivacancy could exist in a collinear form (part a, Fig. 1) or an elbow form (part b, Fig. 1). Our
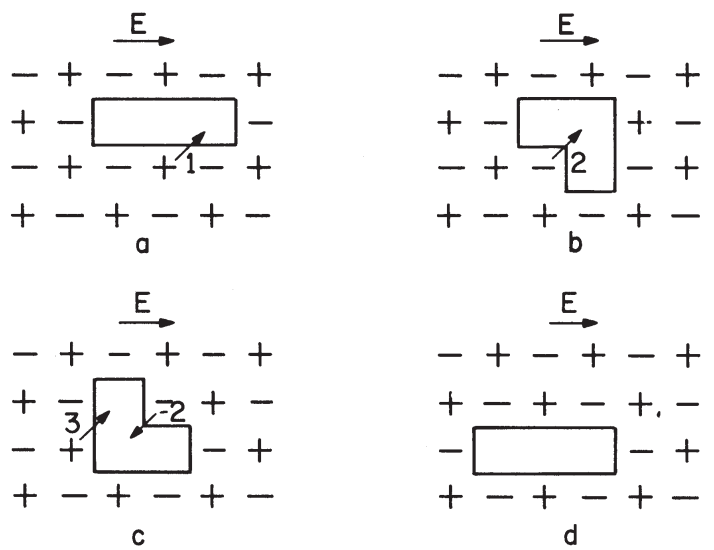

Fig. 1. A typical series of jumps by which a trivacancy could move through the lattice in the presence of an electric field $E$.

simple point ion calculations for a rigid, unpolarizable lattice indicate that, because the repulsive interaction between vacancies of similar charge is larger in the elbow form of trivacancy, the collinear trivacancy is the favored form by about $1.1 \mathrm{eV}$ in $\mathrm{NaCl}$ and 0.9 $\mathrm{eV}$ in $\mathrm{KCl}$ and $\mathrm{RbCl}$.

The equations for determining the concentration of trivacancies can be written as functions of temperature and divalent cation impurity concentration $n_{i}$ as follows:

$$
n_{a} n_{c}=\exp (-g / k T)=n_{0}^{2}(T)
$$




$$
\begin{gathered}
t_{c}=3 n_{a} n_{c}{ }^{2} \exp \left(g_{c} / k T\right)=3 n_{a} n_{0}{ }^{2}(T) \exp \left(g_{c} / k T\right) \\
t_{a}=3 n_{a}{ }^{2} n_{c} \exp \left(g_{a} / k T\right)=3 n_{a} n_{0}{ }^{2}(T) \exp \left(g_{a} / k T\right) \\
n_{c}+t_{c}=n_{a}+t_{a}+n_{i}-n_{k} \\
n_{k} /\left(n_{c}\left(n_{i}-n_{k}\right)\right)=12 \exp (\delta / k T)
\end{gathered}
$$

where the symbols are defined as follows:

$\begin{array}{ll}n_{a} & \text { mole fraction of isolated anion vacancies, } \\ n_{c} & \text { mole fraction of isolated cation vacancies, } \\ n_{i} & \text { mole fraction of divalent impurity cations, } \\ n_{k} & \text { mole fraction of divalent impurity cation-cation vacan- } \\ & \quad \text { cy complexes, } \\ n_{0} & \text { mole fraction of intrinsic Schottky defects, } \\ t_{a} & \text { mole fraction of anion type trivacancies, } \\ t_{c} & \text { mole fraction of cation type trivacancies, } \\ g & \text { free energy of Schottky defect formation, } \\ g_{a} & \text { free energy of binding for an anion type trivacancy, } \\ g_{\mathrm{c}} & \text { free energy of binding for a cation type trivacancy, } \\ \delta & \text { free energy of binding for an impurity-vacancy complex. }\end{array}$

The factor of 12 in equation (5) results from the twelve equivalent orientations of the impurity-vacancy complex. The factor of 3 appears in equations (2) and (3) as a result of the assumption that the trivacancies exist in the collinear form which has three equivalent orientations.

Unfortunately, theoretical calculations of the formation and migration energies of trivacancies have not yet been reported; so we have crudely extended the theoretical calculations for vacancy pairs [9] and Schottky-defects [10]. We have used a rigid unpolarizable lattice approximation which includes point ion Coulomb interactions and nearest neighbor repulsion [10] to compute the work done to take an isolated vacancy and put it next to a vacancy pair. It is predicted that the cation type of trivacancy is favored over the anion type in $\mathrm{NaCl}$ (by $0.6 \mathrm{eV}$ ), $\mathrm{KCl}$ (by $0.3 \mathrm{eV}$ ) and $\mathrm{RbCl}$ (by $0 \cdot 2 \mathrm{eV}$ ). Hence, the ratio of the concentration of trivacancies, essentially all of the cation type, to the concentration of cation vacancies is independent of the impurity concentration, but dependent on the temperature, and has the form

$$
t_{c} / n_{c}=A \exp (B / k T)
$$

where $A$ and $B$ are temperature independent constants. It follows that the ratio of the amount of electrical current carried via a trivacancy mechanism to that carried by a single cation vacancy mechanism is also independent of the impurity concentration and has a form similar to equation (6). Therefore in the high temperature extrinsic regions of conductivity (i.e. $n_{i}>5 n_{0}(T)$ ), the presence of trivacancies might be detectable.

For example, the results for the conductivity of $\mathrm{KCl}$ and $\mathrm{KCl}: \mathrm{SrCl}_{2}$ [7] may be used to estimate the trivacancy contribution to the ionic conductivity of $\mathrm{KCl}: \mathrm{SrCl}_{2}$ crystals. If the 10 per cent discrepancy between the theoretical and experimental results at $750^{\circ} \mathrm{C}$ for pure $\mathrm{KCl}$ [7] is assumed to be the result of a trivacancy contribution to the conductivity, the results from reference [7] (Table 2, Column 2) for the formation entropies and enthalpies of vacancies can be used to compute the trivacancy contribution to the conductivity of $\mathrm{KCl}: \mathrm{SrCl}_{2}$ crystals. The results of these computations (Table 1) show that when the impurity concentration is relatively large, i.e. $n_{i}>5 n_{0}(T)$, the anion vacancy contribution to the conductivity becomes negligible. It can also be shown that in $\mathrm{KCl}: \mathrm{SrCl}_{2}$ crystals any possible interstitial cation contribution to the conductivity would be similarly reduced. Therefore, it can be concluded that a slight 'knee' in the log $(\sigma T)$ vs. $T^{-1}$ plot at high temperatures for alkali halide crystals containing relatively large amounts of a divalent cation impurity would be evidence for the presence of a trivacancy contribution to the conductivity. Such a 'knee' is suggested by the present experimental results for $\mathrm{KCl}: \mathrm{SrCl}_{2}[11]$ and $\mathrm{KBr}$ : $\mathrm{CaBr}_{2}$ [12]. It is hoped that future work will furnish evidence of a more definitive nature.

A typical series of jumps by which a trivacancy can move through the lattice in the presence of an electric field is shown in Fig. 1. After jump (1) the collinear trivacancy (part 
Table 1. The contributions of vacancy mechanisms to the electrical conductivity of $\mathrm{KCl}: \mathrm{SrCl}_{2}$ crystals at $750^{\circ} \mathrm{C}$ as a function of $\mathrm{Sr}$ concentration

\begin{tabular}{lcrr}
\hline & \multicolumn{3}{c}{ Per cent contribution* } \\
Sr mole fraction & $\begin{array}{c}\text { Anion } \\
\text { vacancy }\end{array}$ & $\begin{array}{c}\text { Cation } \\
\text { vacancy }\end{array}$ & $\begin{array}{c}\text { Cationic } \\
\text { trivacancy }\end{array}$ \\
\hline \multirow{2}{*}{0} & $56 \%$ & $34 \%$ & $10 \%$ \\
$100 \mathrm{ppm}$ & $18 \%$ & $63 \%$ & $18 \%$ \\
$200 \mathrm{ppm}$ & $6 \%$ & $73 \%$ & $21 \%$ \\
$500 \mathrm{ppm}$ & $1 \%$ & $761 / 2 \%$ & $22 \frac{1}{2} \%$ \\
$1000 \mathrm{ppm}$ & - & $77 \%$ & $23 \%$ \\
\hline
\end{tabular}

*Computed using the simple theory including association results reported in reference [7], Table 2, column 2 . The intrinsic vacancy concentration was computed to be about $40 \mathrm{ppm}$ at $750^{\circ} \mathrm{C}$.

a, Fig. 1) has the elbow form shown in part $b$ of Fig. 1. The second jump (2) requires that a negative ion move against the force of the electric field, but the potential barrier to such a jump is probably quite low since both of the gate ions are missing from the lattice. However, after jump (2) has occurred the field would increase the probability that the negative ion would jump back across the low barrier into its original site as shown by the -2 labelled jump in part $\mathrm{c}$ of Fig. 1. The trivacancy would remain in a fluctuating elbow form, shown in parts band c, Fig. 1. Then the trivacancy will either return to its original position by a reverse of jump (1) or make a contribution to the conductivity by the occurrence of jump (3).

In summary, these considerations indicate that the anomalous curvature in the intrinsic region of conductivity for $\mathrm{RbCl}, \mathrm{KCl}$ and $\mathrm{NaCl}$ may be the result of a trivacancy contribution. The presence of the cation type of trivacancy might be verified by high temperature conductivity measurements in alkali halide crystals containing large $\left(n_{i}>5 n_{0}\right)$ amounts of a divalent cation impurity. The calculation of the formation and migration energies for trivacancies would seem to be a potentially fruitful theoretical endeavor.
Acknowledgements - We would like to acknowledge the benefit received from discussions with Professor L. M. Slifkin, Dr. M. N. Kabler and Mr. C. L. Marquardt.

U.S. Naval Research Laboratory,

Washington. D.C. 20390,

U.S.A.

R. G. FULLER

M. H. REILLY*

*NRC-NRL postdoctoral research associate.

\section{REFERENCES}

1. FUlLeR R. G. and REILly M. H., Phys. Rev. Lett. 19, 113 (1967).

2. FULLER R. G., REILLY M. H., MARQUARDT C. L. and WELLS Jr., J. C., Phys. Rev. Lett. 20, 662 (1968).

3. ALLNATT A. R. and PANTELIS P., Solid State Commun 6, 309 (1968).

4. LIDIARD A. B., Symposium on Mass Transport in Oxides, oral comments. National Bureau of standards (1967).

5. BEAUMONT J. H. and JACOBS P. W. M., J. Chem. Phys. 45, 1496 (1966).

6. LIDIARD A. B., Phys. Rev. 94, 29 (1954).

7. FULLER R. G., MARQUARDT C. L., REILLY M. H. and WELLS Jr., J. C., To be published.

8. SOPTITZ P. and TELTOW J., Phys. Status Solidi 23, 9 (1967).

9. TOSI M. P. and FUMI F. G., Nuovo Cim. 8, 95 (1958).

10. TOSI M. P. and DOY AMA M., Phys. Rev. 151, 642 (1966).

11. See, for example, the four highest temperature data points in Fig. 4, reference [7].

12. BARR L. W., Private communication. 